David R. Gambling MB BS DRCOG FRCPC, Patrick Yu MD Colm Cole MD FRCPC, Graham H. McMorland MB CH B DA FRCPC, Lynne Palmer RN

\title{
A comparative study of patient controlled epi- dural analgesia (PCEA) and continuous infusion epidural analgesia (CIEA) during labour
}

In a randomised, single-blinded, placebo-controlled study. 27 parturients in labour receiving epidural 0.125 per cent bupivacaine, were assessed to evaluate the efficacy of parientcontrolled epidural analgesia (PCEA) compared with continuoses infusion epidural analgesia (CIEA). Group $A(n=14)$ received a background infusion of $4 \mathrm{ml} \cdot \mathrm{hr}^{-1} 0.125$ per cent bupivacaine, with further $4 \mathrm{ml}$ aliquots, self-administered, as required (up to $16 \mathrm{ml} \cdot \mathrm{hr}^{-1}$ ). Group $B$ in $=11$ ) received a continuous infusion of $12 \mathrm{ml} \cdot \mathrm{hr}^{-1}$ through the same PCA apparatus, but with the demand-button deactivated. Both groups were similar in respect to age, height, weight, duration and outcome of labour, birthweight and neonatal Apgar scores. Patients in Group A (PCEA) received significantly less local anaesthetic than those in Group B (11.2 vs $\left.15.2 \mathrm{mg} \cdot \mathrm{hr}^{-1}\right)$. Pain relief was similar in both groups. Patients expressed overall satisfaction with PCEA, appreciating control over their own pain relief and less reliance on medical staff. PCEA is a safe, effective means of providing optimal analgesia during labour, with minimal local anaesthetic requirement.

\section{Key words}

ANAESTHESIA: obstetric; ANAESTHETIC TECHNIQUES: epidural; ANAESTHETICS LOCAL; bupivacaine; EQUIPMENT: patient-controlled analgesia.

From the Department of Anaesthesia, University of British Columbia and Grace Hospital, Vancouver, British Columbia.

Presented in part at the 19th Annual Meeting of the Society for Obstetric Anaesthesia and Perinatology in Halifax, N.S., May 1987

Supported in part by a grant from the Faculty of Medicine Research Coordinating Committee of the University of British Columbia.

Address correspondence to: Dr. D.R. Gambling, Department of Anaesthesia, Grace Hospital, 4490 Oak Street, Vancouver, British Columbia, V6H 3 V5.
Patient-controlled analgesia (PCA) via the intravenous route has increased in popularity in the last two decades due to its efficacy in providing optimal postoperative analgesia. The technique is associated with less analgesic requirement when compared with more conventional dosing regimes and provides user-satisfaction, reducing patient anxiety associated with the anticipation of pain. PCA in obstetrics was first described by Scott ${ }^{1}$ (1970) using an apparatus which provided an intravenous infusion of meperidine, the rate of which was varied by a hand-held clamp.

Using more sophisticated PCA systems, other investigators have applied the technique to intravenous analgesia during labour ${ }^{2-5}$ and for post-Caesarean section analgesia. $^{6,7}$ Most of the studies of women in labour were uncontrolled, but suggested that these woman were capable of controlling their own pain relief, and used less analgesia when compared with continuous infusion methods.

Epidural infusions of local anaesthetic provide supcrior analgesia during labour to that achieved with intravenous narcotics. Traditionally, a continuous epidural technique has implied that local anaesthetic is administered by either a physician or midwife, at the patient's request, on an intermittent basis via an epidural catheter. The use of continuous infusion epidural analgesia (CIEA) with local anaesthetic has become more popular, as it provides a more consistent level of analgesia during labour than the intermittent technique. Unfortunately, these infusions are associated with a greaticr incidence of motor block with higher concentrations of local anaesthetics. Inadequate analgesia requirin $n_{y}$ additional supplementation is sometimes observed when more dilute solutions are used. Patients receive a $c$ nstant infusion of local anaesthetic, without regard to their individual neads, and the possibility of producing a high sensory block is always present in the unmonitored patient. Comparabie analyesia using the continuous infusion technique may alsc resuire a higher dose of local anaesthetic. ${ }^{8}$ 
Patient controlled administration of epidural narcotics for postoperative pain relief has been reported ${ }^{9}$ and the same grotp has also demonstrated less narcotic requirement with an epidural PCA technique compared with intravenous PCA in postoperative patients. ${ }^{10}$ Patient controlled epidural infusions of local anaesthetic for analgesia during labour (PCEA) has not been described previously. Consequently we designed a randomised, single-blinded, placebo controlled study which allowed us to compare the established CIEA technique with the untried PCEA technique, using 0.125 per cent bupivacaine during labour.

\section{Methods}

Twenty-seven ASA physical status I or II nulliparous parturients in established term labour were selected from our low risk delivery area, each with a singleton fetus in vertex presentation. All patients had requested epidural analgesia for labour and delivery. Following approval from the Screening Committee for Research Involving Human Subjects, informed consent was obtained from each patient.

Epidural catheterisation, using a standard technique, was performed with the patient in the left lateral decubitus position. Catheter function was assessed using a $3 \mathrm{ml}$ test dose of 0.25 per cent bupivacaine followed by a further 5 $\mathrm{ml}$ of the same solution to achieve adequate analgesia. Once the patient was comfortable, an infusion of 0.125 per cent bupivacaine was started using the PCA system.

We used a PCA machine developed by the Biomedical Engineering Department of the University of British Columbia, consisting of a modified IVAC 530 with a custom control device. This system, a modification of the one described in this journal earlier," allowed us to provide a continuous infusion of local anaesthetic solution, with the ability of giving additional incremental boluses by activation of the patient demand button. The rate of infusion, the incremental dose and the lockout period were all programmable. $\wedge$ modified calculator timer and printer recorded all patient demands. Safety features of the system included having all the program controls, and the infusion reset switch, locked behind a plexiglass door.

The patients were randomly assigned to one of two groups. Group A patients had the PCA system set to infuse a background continuous infusion rate of $4 \mathrm{ml} \cdot \mathrm{hr}^{-1}$. In addition, they could trigger the device to deliver a further $4 \mathrm{ml}$ of the 0.125 per cent bupivacaine solution, with a lockout interval of 20 minutes. Patients in Group A were thus able to titrate their bupivacaine requirements from a minimum of $4 \mathrm{ml}(5 \mathrm{mg}$ ) per hour to a maximum of $16 \mathrm{ml}(20 \mathrm{mg})$ per hour.

Group B patients had the PCA system set to deliver a continuous infusion of $12 \mathrm{ml} 0.125$ per cent bupivacaine per hour, but without the ability to receive extra boluses, since the patient demand button was deactivated. So patients in Group B received a fixed continuous infusion of $12 \mathrm{ml}(15 \mathrm{mg}$ ) of bupivacaine per hour.

Patients in both groups were unaware as to their group assignment and received the same instructions to activate the patient demand button as soon as they required additional analgesia. Every patient in the study expected to get pain relief after making a demand. Supplemental analgesia, provided by the anaesthetist, was given if patients in either group complained of inadequate analgesia despite activating the demand button. Bupivacaine $0.25,0.5$ or carbonated lidocaine 1.73 per cent were used for persistent pain, most often caused by a "missed" segment or persistent occipito-posterior position.

Overall quality of analgesia was assessed using a $10 \mathrm{~cm}$ visual linear analogue scale, representing a continum of the patient's opinion of the degree of pain. ${ }^{12}$ Sensory analgesia was determined by loss of sensation to cold, using ice, and the degree of motor block was assessed clinically, using Bromage's scale. ${ }^{13}$ Patients were assessed at 30 minutes after epidural insertion and then at hourly intervals. Maternal blood pressure was measured every five minutes after the epidural insertion, for 15 minutes, and then every 30 minutes. Blood pressure was also checked every five minutes, for 15 minutes, after each patient demand. The nurse in attendance was made aware of each demand by communication with the parient. Fetal heart rates were monitored continuously throughout labour and neonates were evaluated by Apgar scores at one and five minutes.

Demographic data were analysed using Chi Square

TABLE I Demographic data (mean \pm SEM)

\begin{tabular}{|c|c|c|}
\hline & $P C E A(n=14)$ & $C I E A(n=I I)$ \\
\hline Maternal age: (yr) & $28 \pm 1.3$ & $29 \pm 1.2$ \\
\hline Height $(\mathrm{cm})$ & $160 \pm 1.6$ & $163 \pm 1.8$ \\
\hline Weight (kg) & $71 \pm 3.2$ & $73 \pm 2.1$ \\
\hline \multicolumn{2}{|l|}{ Cervical dilatation at stant of } & $4.3 \pm 0.3$ \\
\hline \multicolumn{3}{|l|}{ Duration of labour (hr) } \\
\hline 1st stage & $14.4 \pm 1.5$ & $14.3 \pm 1.9$ \\
\hline 2nd stage & $1.8 \pm 0.2$ & $2.0 \pm 0.3$ \\
\hline \multicolumn{3}{|l|}{ Mode of Delivery } \\
\hline Spontanecus vaginal delivery & 6 & 5 \\
\hline Forceps assisted & 6 & 5 \\
\hline Caesarean section & 2 & 1 \\
\hline Fetal birthweight $(\mathrm{kg})$ & $3.28 \pm 0.15$ & $3.38 \pm 0.16$ \\
\hline \multicolumn{3}{|l|}{$\begin{array}{l}\text { No. of neonates } \\
\text { with Apgar score }<7\end{array}$} \\
\hline at 1 minute & 3 & 3 \\
\hline at 5 minutes & 1 & 1 \\
\hline
\end{tabular}




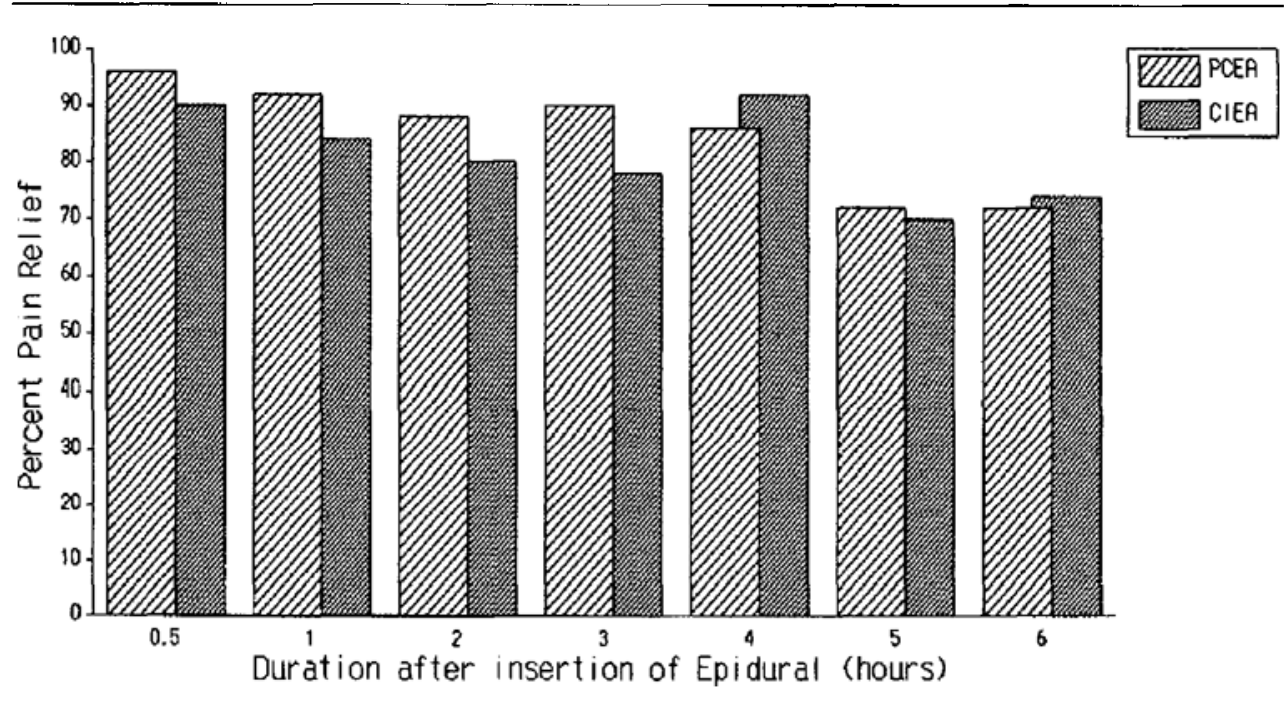

FIGURE 1 Patient analgesia obtained: PCEA vs CIEA (mean).

analysis for ordinal data and the two sample $t$ test for interval data. Epidural requirements were analysed using the two sample $t$ test and pain score data at each assessment interval, analysed using the Mann Whitney $U$ test. Chi square analysis was also used to assess the differences in patient analgesia between the two groups.

\section{Results}

Twenty-seven patients were studied, but two had to be withdrawn from the study. One patient had her continuous infusion discontinued because of machine failure, and the other, despite adequate analgesia, became very distressed due to fatigue.

Maternal age, weight, height, gravidity, neonatal gestational age and weight, duration and complications of labour and delivery are listed in Table I. There were no significant differences between the two groups.

The duration of epidural infusion, the number of patient demands made per hour and the amount of bupivacaine required to maintain the epidural infusion are listed in Table II.

Patients in the PCEA group made more demands per hour $(1.9 \pm 0.4$ vs $1.2 \pm 0.24)$, as they had to titrate their analgesia, but overall required less bupivacaine during labour than those in the CIEA group. Group A patients received a mean hourly bupivacaine dose of $11.2 \pm$ $0.85 \mathrm{mg} \cdot \mathrm{hr}^{-1}$ compared with $15.2=0.5 \mathrm{mg} \cdot \mathrm{hr}^{-1}$ in Group B.

This hourly dose of bupivacaine does not include the
TABLE II Epidural requirements (mean \pm SEM)

\begin{tabular}{lccc}
\hline & PCEA (n= I4) & CIEA $(n=11)$ & \\
\hline $\begin{array}{l}\text { Duration (hours) } \\
\text { No. of demands } \\
\text { per hour }\end{array}$ & $7.0 \pm 0.6$ & $5.8 \pm 0.6$ & NS \\
$\begin{array}{l}\text { Dose of bupivacaine } \\
\text { required per hour of } \\
\text { infusion mg } \text { hr }^{-1}\end{array}$ & $1.9 \pm 0.4$ & $1.2 \pm 0.24$ & NS \\
\hline
\end{tabular}

initial bolus of bupivacaine ( $15 \mathrm{mg}$ ) given at epidural insertion. This was done in order to compensate for the artifactual increase in dose requirements that would have been seen in patients with short durations of epidural infusion.

The degree of analgesia obtained is depicted in Figure 1. The degree of analgesia, or percentage of pain relief is estimated by subtracting from 100 , the percentage of residual pain. The latter is calculated by dividing the patient's pain score at the time of assessment, by her pain score obtained prior to epidural insertion. There were no significant differences between groups in the pain relief obtained.

Pain scores, prior to epidural insertion, were the same in both groups, with a mean score of 8.6 ( $\mathrm{SE} \pm 0.4)$ in Group $A$ and 9.0 ( $S E \pm 0.24$ ) in Group B.

The mean height of sensory blockade for both groups was the same ( $T_{9}$ ) as depicted in Figure 2 but adjustments were made in group $B$ patients' rates of infusion, when the 


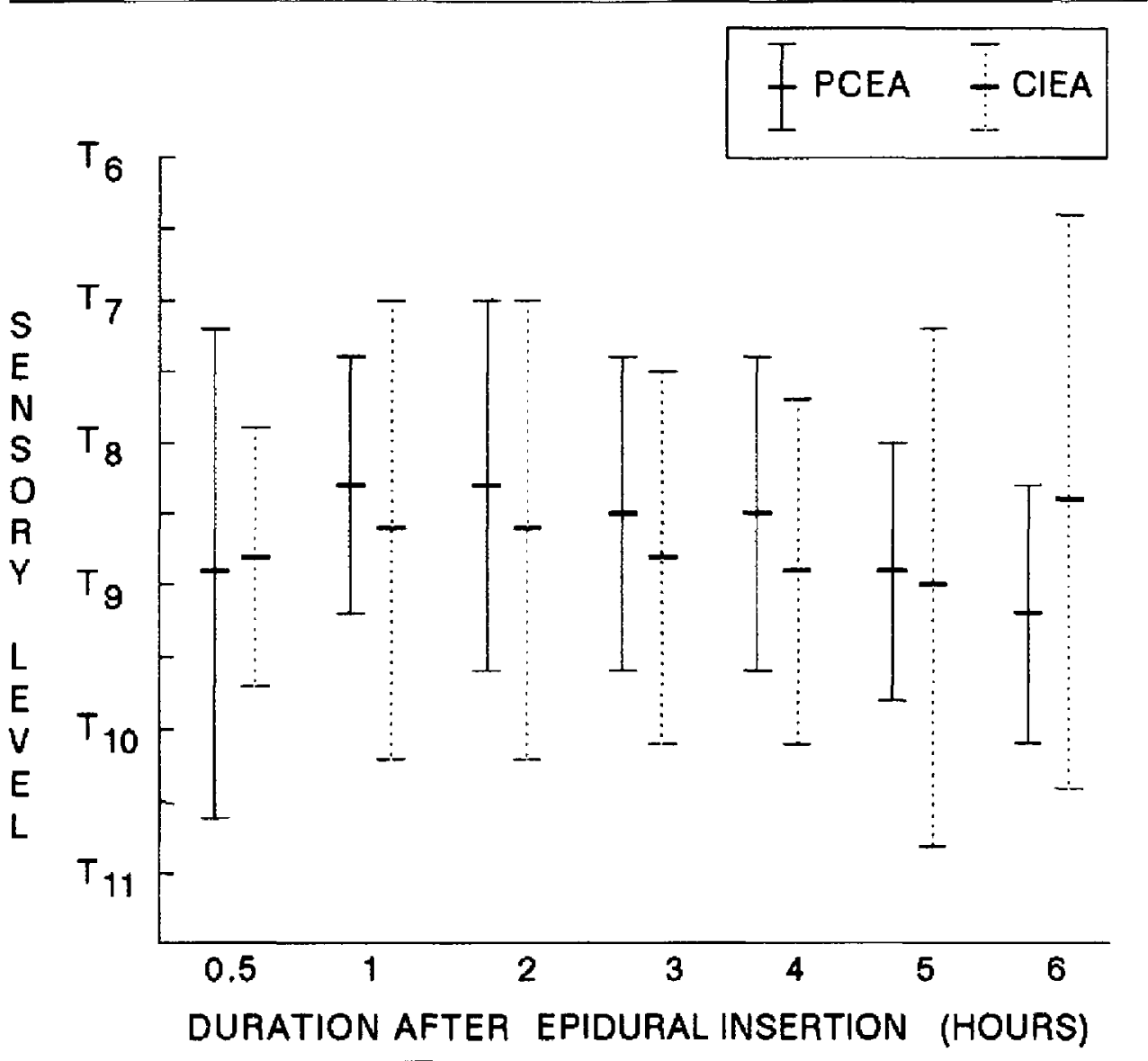

FIGURE 2 Hcight of sensory blockade (mean \pm SD).

level was higher than $T_{6}$. Patients in the PCEA group achieved various sensory levels of analgesia. There were some who were quite satisfied with 30 per cent residual pain, whereas others, although not in distress, aimed for absolute pain relief. This suggests that patient satisfaction does not necessarily equate with the degree of analgesia.

Three patients in Group B required supplemental analgesia despite a seemingly adequate segmental sensory level. Two patients in each group received an additional dose of carbonated lidocaine because of a missed dermatomal segment of analgesia.

A marked placebo effect ( -30 per cent) was observed in both groups. This was manifest as considerable pain relief, almost immediately after pushing the demand button.
There were no significant differences in one and five minute Apgar scores between the two groups.

Minimal motor blockade was seen in patients from both groups.

There were no mishaps due to tampering with or malfunction of the PCA machine.

\section{Discussion}

A major goal in obstetrics is to provide optimal analgesia to each patient during labour. Epidural analgesia can improve the efficacy of pain relief by providing a continuous infusion of local anaesthetic. This is often accomplished with large doses of local anaesthetic which provide almost complete analgesia. However, there are 
patients who would prefer to have some sensation of their contractions. The optimal level of analgesia is hard to achieve with the more traditional methods, such as intermittent bolusing or CIEA, but we have shown that women in labour are capable of accomplishing this themselves. Moreover the resultant optimal analgesia is achieved with a lower overall local anaesthetic requirement using the PCEA technique.

We chose to study the efficacy of 0.125 per cent bupivacaine using the PCEA apparatus, as this concentration has been shown by several authors to provide good analgesia during labour with minimal motor block and without significant adverse effects on the neonate. ${ }^{14,15}$ The dosage of bupivacaine used in our continuous infusion group ( $15 \mathrm{mg} \cdot \mathrm{hr}^{-1}$ ) was comparable to that used by other investigators.

Both groups achieved comparable analgesia without the bias of having received special treatment, but subtle differences in the degree of analgesia are difficult to detect, due to a lack of sensitivity of the visual analogue pain scale.

The drawback to this method, as with all PCA techniques, is the need for additional, often expensive infusion systems. In addition, extra effort to instruct the patient and educate the nursing staff is required. The technique is not without risk, despite built-in safety features and strict protocols, and mishaps have been reported with PCA devices. ${ }^{16}$

The expense of the infusion systems may be offset in the long run by increased efficiency in nursing time and decreased drug utilisation. PCEA allows the anaesthetist to modify his or her role in the management of labour pain by assisting the patient in titrating her own pain relief. The patient then assumes a degree of responsibility and control over her experience during labour, which our study patients all appreciated. However, patient selection is required as she must understand the concept of epidural analgesia and be willing to accept some control over her pain relief. Patients exhausted atter a long arduous labour without an epidural may not be the best candidates for the PCEA technique, as they often fall asleep when they become comfortable. In the suitable, alert patient, little interference should be required once she realizes the simplicity of the process of providing analgesia for herself.

We do not advocate the use of this technique in the unmonitored patient, in that nursing staff and in-house physicians should be readily available to recognize and deal with inadvertent intravenous and subarachnoid migration of the epidural catheter, as with any method employed to provide epidural analgesia. Of the currently available methods though, we feel that PCEA using small, dilute volumes of local anaesthetics, is possibly the least likely to cause maternal morbidity and mortality in the event of catheter migration.

Further work with PCEA is required to compare the efficacy of different concentrations of bupivacaine, various bolus volumes and different lockout periods in the labouring woman.

In summary, PCEA is a satisfactory method of providing epidural analgesia during labour, allowing greater patient participation and control over her own pain relief than the more conventional methods. We have demonstrated that less local anaesthetic is required during labour with PCEA, compared with a CIEA technique.

\section{Acknowledgment}

The authors wish to thank Ms. Lois Obenauer for her secretarial assistance in preparation of this manuscript.

\section{References}

1 Scott JS. Obstetric analgesia: a consideration of labour pain and a patient-controlted technique for its relief with meperidine. Am J Obstet Gynecol 1970; 106: 959-78.

2 Evans JM, MacCarthy J, Rosen $M, H a g g$ MI. Apparatus for patient-controlled administration of intravenous narcotics during labour. Lancet 1976; X: 17-18.

3 Robinson O, Rosen M, Evans JM, Revill SI, David H, Recs GAD. Self-Administered intravenous and intramuscular pethidine: controlled trial in labour. Anaesthesia 1980; 35: 763-70.

4 Harper NJN, Thomson J, Bryshaw SA. Experience with self-administered pethidine with special reference to the general practitioner obstetric unit. Anaesthesia 1983; 38 : 52-5.

5 Barrier G, Harmer $M$. Patient controlled analgesia in obstetrics, Chapter 10 (170-9). In: Patient-Controlled Analgesia. Harmer H, Rosen M, Vickers MD (Eds), Oxford, Blackwell Scientific Publication, 1985.

6 Patel R, McKenzie R. Patient-controlled analgesia after Cesarian section. Post Grad Medicine 1986. Special Report Aug 28: 23-8.

7 Harrison DM, Sinarra RS. Oxymorphone for use in patient-controlled analgesia: the ideal PCA drug? (Abstract). Anesth Analg 1987; 66: S78.

8 Morison $D H$, Smedstad $K G$. A comparative study of continuous and intermittent epidural analgesia for labour and delivery (Abstract). Presented at the 18th Annual Meeting of the Sociaty for Obstetric Anesthesia and Perinatology 1986. Page 54.

9 Sjostrom S, Tamsen A, Hartvig P. Patient controlled analgesia with epidural opiates: a preliminary report. In: Patient Controlled Analgesia, Chapter 10: 156-9. Harmer H, Rosen M, Vickers MD (Eds). Oxford Blackwell Scientific Publication, 1985 
10 Tamsen A, Sjastrom S, Harnig $P$. The Uppsala experience of patient-controlled analgesia. In: Foley KM, Inturussi CE (Eds). Advances in Pain Research and Therapy, Vol 8. New York, Raven 1986.

I] Bates CP, McEwen JA, Leighton KM. Modification of IVAC 530 infusion pump for patient controlled analgesia. Can J Anaesth 1987; 34: 2 200-3.

12 Revill SI, Robinson JO, Rosen M, Hogg MIJ. The reliability of a linear analogue for evaluating pain. Anaesthesia 1976; 31: 1191-8.

13 Bromage PR. A comparison of the hydrochlcride and carbon dioxide salts of lidocaine and prilocaine in epidural aralgesia. Acta Anaesthesiol Scand 1965; 16: 55.

14 Abboud TK, Afrasiabi A, Sarkis $F$ et al. Continuous infusion epidural analgesia in parturients receiving bupivacaine, chloroprocaine, or lidocaine - matemal, fetal and neonatal effects. Anesth Analg 1984; 63: 421-8.

15 Kenepp NB. Cheek TG, Gutsche BB. Bupivacaine: continuous infusion epidural analgesia for labor (Abstract). Anesthesiology 1983, 59: A407.

16 White PF. Mishaps with Patient-controlled Analgesia. Anesthesiology 1987; 66: 1, 81-2.
Résumé

Dans une étude randomisée, à simplc insu, et contrôlée par du placebo, 27 parturientes en travail ayant une épidurale 0.125 pour cent de bupivacaine, etaient ettudiées afin d'évaluer l'efficacité de l'analgésie épidurale contrólée par le patient (PCEA) comparé dal analgésie épidurale par perfusion continue (CIEA) Le groupe $A(n=14)$ a reçu une perfusion continue de $4 \mathrm{ml} \cdot \mathrm{hr}^{-1}$ de 0.125 pour cent de bupivacaine avec des doses de "rajout" de $4 \mathrm{ml}$ que les patientes $s$ 'administraient selon le besoin (jusqu'd $\left.16 \mathrm{ml} \cdot \mathrm{hr}^{-1}\right)$. Le groupe $B(n=11)$ a reçu une perfusion continue de $12 \mathrm{ml} \cdot \mathrm{hr}^{-1}$ travers te même appareil $\mathrm{PCA}$ sans que la patiente soit capable de s'adiministrer elle-même sur demande l'analgésique. Les deux groupes étaient similaires par rapport à l'âge, ta taille, le poids, la durée et l'issue du travail. le poids du bébé et le score néonatal d'Apgar. Les patients du groupe $A(P C E A)$ ont reçu significativement moins d'anesthesique local que celles du groupe $B\left(11.2\right.$ versus $\left.15.2 \mathrm{mg} \cdot \mathrm{hr}^{-1}\right)$. Le soulagement de la douleur était similaire dans les deux groupes. Les patientes ont exprimé leur satisfaction générale avec la PCEA appréciant le contrôle personnel qu'elles avaient sur leur douleur ce qui leur procurait moins de dépendance sur l"équipe médicale. La PCEA est un moyen sécuritaire efficace fournissant une amalgésie optimale durant le travail avec un minimum d'agents anesthésiques locaur. 